Article

\title{
Polyalthia Clerodane Diterpene Potentiates Hypoglycemia via Inhibition of Dipeptidyl Peptidase 4
}

\author{
Po-Kai Huang ${ }^{1}$, Shian-Ren Lin ${ }^{1}{ }^{\mathbb{D}}$, Jirawat Riyaphan ${ }^{1}{ }^{\mathbb{C}}$, Yaw-Syan Fu ${ }^{2}$ and \\ Ching-Feng Weng ${ }^{1, *}$ \\ 1 Department of Life Science and Institute of Biotechnology, National Dong Hwa University, Hualien 97401, \\ Taiwan; kevin7699402@hotmail.com (P.-K.H.); d9813003@gms.ndhu.edu.tw (S.-R.L.); \\ 810254005@gms.ndhu.edu.tw (J.R.) \\ 2 Departmental of Biomedical Science and Environmental Biology, Kaoshiung Medical University, \\ Kaoshiung 80708, Taiwan; m805004@kmu.edu.tw \\ * Correspondence: cfweng@gms.ndhu.edu.tw; Tel.: +886-3-890-3637; Fax: +886-3-863-0255
}

Received: 23 December 2018; Accepted: 24 January 2019; Published: 27 January 2019

\begin{abstract}
Serine protease dipeptidyl peptidase 4 (DPP-4) is involved in self/non-self-recognition and insulin sensitivity. DPP-4 inhibitors are conventional choices for diabetic treatment; however, side effects such as headache, bronchus infection, and nasopharyngitis might affect the daily lives of diabetic patients. Notably, natural compounds are believed to have a similar efficacy with lower adverse effects. This study aimed to validate the DPP-4 inhibitory activity of clerodane diterpene 16-hydroxycleroda-3,13-dien-15,16-olide (HCD) from Polyalthia longifolia, rutin, quercetin, and berberine, previously selected through molecular docking. The inhibitory potency of natural DPP-4 candidates was further determined by enzymatic, in vitro Caco-2, and ERK/PKA activation in myocyte and pancreatic cells. The hypoglycemic efficacy of the natural compounds was consecutively analyzed by single-dose and multiple-dose administration in diet-induced obese diabetic mice. All the natural-compounds could directly inhibit DPP-4 activity in enzymatic assay and Caco-2 inhibition assay, and HCD showed the highest inhibition of the compounds. HCD down-regulated LPS-induced ERK phosphorylation in myocyte but blocked GLP-1 induced PKA expression. For in vivo tests, HCD showed hypoglycemic efficacy only in single-dose administration. After 28-days administration, HCD exhibited hypolipidemic and hepatoprotective efficacy. These results revealed that HCD performed potential antidiabetic activity via inhibition of single-dose and long-term administrations, and could be a new prospective anti-diabetic drug candidate.
\end{abstract}

Keywords: dipeptidyl peptidase 4; hyperglycemia; natural compound inhibitors; molecular docking; clerodane diterpene 16-hydroxycleroda-3,13-dien-15,16-olide

\section{Introduction}

Type 2 diabetes mellitus (TII DM) is a chronic disease that occurs in 366 million people worldwide and the effects of TII DM result in cardiovascular disease, obesity, eye problems, kidney problems, problems with the feet, nerves or microvascular complications, damage to large blood vessels, as well as brain, legs and macrovascular complications [1]. According to statistics in 2016, the disability-adjusted-life-years (DALYs) rate of diabetes is 1887.6/100,000, which has become a burden for all of society [2]. Medication is the main regimen for treating diabetes and there are numerous varieties of hypoglycemic agents available, such as sulfonylurea, $\alpha$-glucosidase inhibitors, $\mathrm{Na}^{+} /$glucose co-transporter inhibitors, and biguanides [3]. Noticeably, inhibitors of dipeptidyl peptidase 4 (DPP-4) have an alternative impact on diabetic strategy. 
DPP-4 (also named as adenosine deaminase complexing protein 2, ADCP 2) is a serine exopeptidase that is a cleaved Xaa-Pro dipeptide from the N-terminus of oligo- and poly-peptides [4]. Two types of DPP-4 are found in the body: soluble (sDPP-4) and membrane-bound (mDPP-4) forms that are only different in the presence or absence of cytoplasmic region at the N-terminal [5]. SDPP-4 is secreted from bone marrow, which can activate T-cell proliferation and may be involved in self/non-self-recognition [6,7]. In addition, mDPP-4 is located on the outside of the cell membrane in the liver, spleen, lung, brain, heart, and vascular smooth muscle cells [8]. The biological role of m DPP-4 is associated with insulin sensitivity regulation by degrading incretin like glucagon-like peptide 1 (GLP-1), which stimulates insulin biosynthesis, inhibits glucagon secretion, slows gastric emptying, reduces appetite, and stimulates regeneration of pancreatic $\beta$-cells [9]. Accordingly, DPP-4 inhibition becomes a novel approach to overcome insulin insensitivity associated with TII DM. Currently, synthetic DPP-4 inhibitors like sitagliptin and vildagliptin have clinically been used to treat TII DM. Interestingly, researchers have also reviewed current DPP-4 inhibitors as interacting with diuretics, warfarin, digoxin, and monoamine oxidase inhibitors, which alters DPP-4 metabolism or vice versa [10]. However, all synthetic DDP-4 compounds may occasionally contain adverse- or side-effects, and herbal medicines are believed to have lower adverse effects with similar efficacy [11]. Thus, scientists and physicians have paid more attention to the impact of searching for novel DPP-4 inhibitors from natural sources to provide new insights for TII DM patients.

Generally speaking, docking is a simulation of ligand-receptor interaction using computational algorithms [12]. Compared to other screening methods like enzymatic assay or in vitro cell assay, molecular docking can collect ligand candidates from a huge amount of compounds, which accelerates the progression of drug development [13]. In our previous study, 68 natural compounds were docked with DPP-4 protein module and the strength of interaction ranked by docking score. 16-hydroxycleroda-3,13-dien-15,16-olide (HCD) from Polyathia longifolia, rutin and quercetin from Toona sinensis, and berberine from Coptis chinensis, whose docking scores were 79.257 (rutin), 68.290 (HCD), 65.341 (quercetin), and 65.248 (berberine), respectively, obtained the 1st, 3rd, 5th, and 6th places of 68 screened natural compounds [14]. The data revealed that HCD, rutin, quercetin, and berberine might strongly interact with DPP-4 and which might be potential inhibitors. This study examined the inhibitory potency of selected DPP-4 inhibitor candidates through in vitro methods and further tested their hypoglycemic efficacy via short-term and long-term administration in vivo.

\section{Results}

\subsection{In Vitro Inhibition of DPP-4 Activity by Natural Compounds}

To test which natural compounds directly inhibited the activity of the DPP-4 enzyme, $100 \mu \mathrm{M}$ of rutin, quercetin, berberine, HCD, and two known DPP-4 inhibitors (Sitagliptin and hemifumarate) were used. When compared with original DPP-4 enzyme, all test samples showed an inhibition effect. The highest inhibition was found with HCD. Compared with hemifumarate, HCD showed higher inhibitory potency. Furthermore, compared with sitagliptin, the top three natural compounds showed lower (HCD and berberine) inhibitory potency than that of sitagliptin, which indicated natural compounds could reduce DPP-4 activity, but the inhibitory potency was not higher than clinical sitagliptin (Figure 1). Therefore, only the highest-potent candidate HCD was subsequently tested by an in vitro cellular assay. 


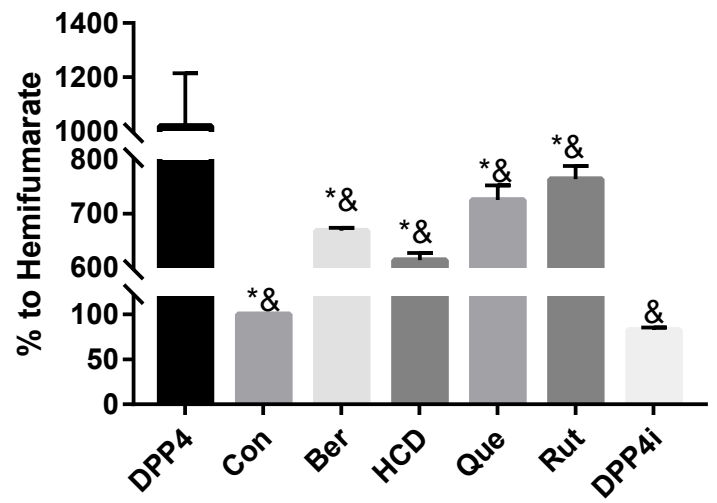

Figure 1. In vitro enzymatic assay of docked natural compounds against DPP-4. Natural compounds were mixed with DPP-4 and enzyme substrate and then the measured absorbance change at $405 \mathrm{~nm}$. Result of DPP-4/hemifumarate (Con) was set at 100\%. All data were represented as mean \pm SD in triplicates from three independent experiments. ${ }^{*} p<0.05$ was marked in the column significantly different with Con and \& $p<0.05$ with DPP4i. rutin (Rut), quercetin (Que), berberine (Ber), 16-hydroxycleroda-3,13-dien-15,16-olide (HCD).

On the other hand, mDPP-4 was a membrane-bound protein on the enterocyte, so DPP-4 activity inhibition of the two highest-potent compounds in enzymatic tests could also be determined by using enterocytic-mimic Caco-2 cells [15]. In $12 \mathrm{~h}$ and $24 \mathrm{~h}$ treatments, HCD showed inhibition in a dose-dependent fashion (Figure 2). However, the reducing fold of HCD was lower than sitagliptin. When the results were taken together, natural compounds selected by in silico could directly inhibit DPP-4 activity, but the inhibitory potency would not be higher than sitagliptin. Next, the inhibitory potency was evaluated at a cellular level.

(A) $12 \mathrm{~h}$

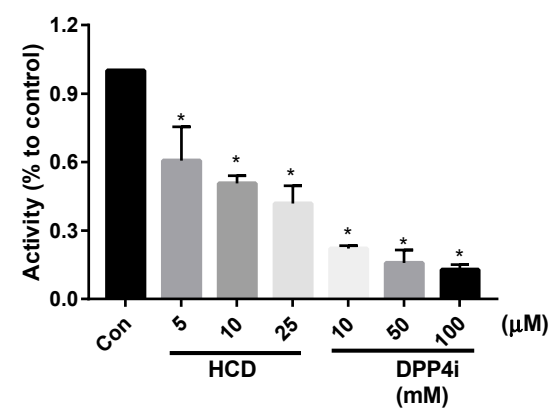

(B) $24 \mathrm{~h}$

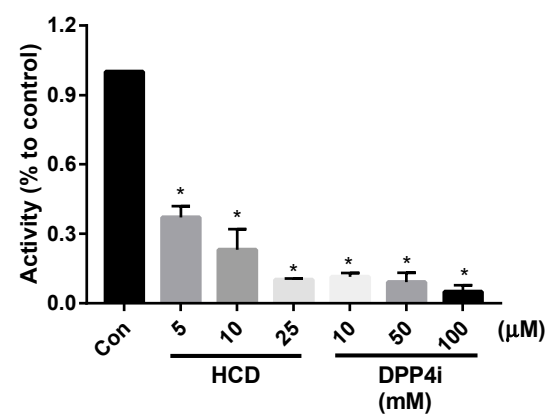

Figure 2. Alteration of Caco-2-bound DPP-4 activity by docked natural compounds. 16-hydroxycleroda-3,13-dien-15,16-olide (HCD) and sitagliptin (DPP4i) were treated with differentiated Caco-2 for (A) $12 \mathrm{~h}$ and (B) $24 \mathrm{~h}$ and DPP-4 activity determined. All data were converted into a ratio with the untreated control and shown as mean \pm SD from three independent experiments. ${ }^{*} p<0.05$ was marked in the column significantly different with Con.

\subsection{Natural Compounds against DPP-4 Expression and Downstream Signaling Pathway}

Cellular DPP-4 has mDPP-4 and sDPP-4 as two forms, which act as different characters within cellular response regulation [16]. sDPP-4 could be a myokine that induces smooth muscle cell proliferation via up-regulating pro-inflammatory MAPK signaling pathway [17]. Thus, the inhibitory potency of DPP-4 in cellular level was determined via two different approaches: ERK-phosphorylation in smooth muscle cells and PKA expression in pancreatic cells. First, ERK-phosphorylation in LPS-induced smooth muscle cells could be used as a marker for intracellular DPP-4 activity. After 10 and $30 \mathrm{~min}$ of $10 \mathrm{ng} / \mathrm{mL}$ LPS stimulation, C2C12 cells were treated with three concentrations of natural compounds and ERK phosphorylation levels measured. These results were associated with enzymatic 
assay, all tested natural compounds could reduce ERK phosphorylation in C2C12 cells, which indicated that these compounds could block sDPP-4 activity (Figure 3). However, all concentrations of HCD except $45 \mu \mathrm{M}$ showed no inhibitory effect in 30 min treatment, which was designated as the lower inhibition potency of these two compounds at higher inflammation levels (Figure 3).

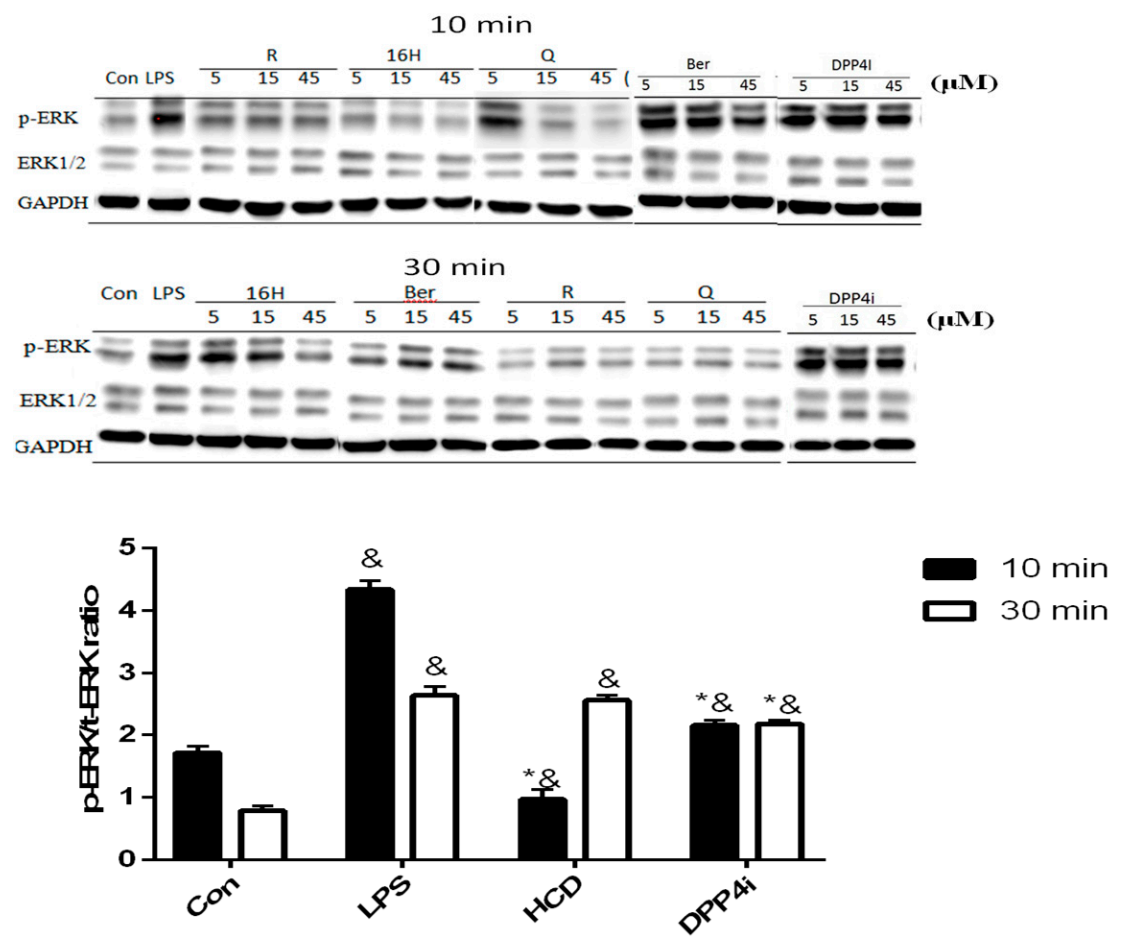

Figure 3. ERK phosphorylation change after selected natural compounds' treatment. Myocyte were stimulated by LPS and then treated with, 16-hydroxycleroda-3,13-dien-15,16-olide (HCD \& 16H) and sitagliptin (DPP4i) for 10- and 30-min. Ratio of phosphorylated and total ERK levels were detected by Western blotting and normalized with GAPDH. All data were mean $\pm \mathrm{SD}$ from three independent experiments. ${ }^{*} p<0.05$ was marked in the column significantly different to LPS and "\&" with DPP4i.

Moreover, mDPP-4 could be found in the pancreatic islet with the inhibition of up-regulated insulin secretion by PKA-dependent signaling [18,19]. The inhibitory potency of DPP-4 was measured by co-treatment with GLP-1 in pancreatic cells. PKA increased in GLP-1 and Ex-4 treated cells revealed a positive correlation between intracellular PKA and extracellular GLP-1. However, $45 \mu \mathrm{M}$ of HCD treatment significantly blocked PKA expression. Even co-treating with GLP-1 and Ex-4 could not restore the PKA expression (Figure 4) Combining these data with the ERK-phosphorylation and DPP-4 inhibition results, HCD might not activate DPP-4 activity Therefore, this hindered that HCD strongly inhibited PKA expression through a signaling pathway other than GLP-1. 


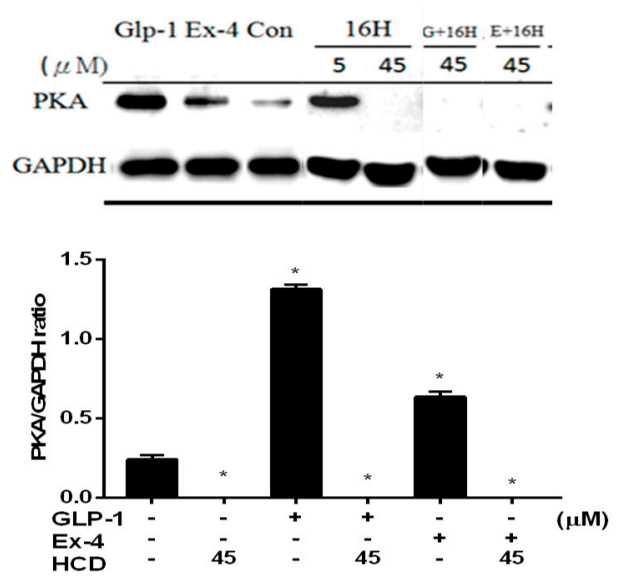

Figure 4. PKA level change after selected natural compounds' treatment. Pancreatic cells were treated with and 16-hydroxycleroda-3,13-dien-15,16-olide (HCD \& 16H) with/without GLP-1 (natural incretin) and exendin-4 (Ex-4, GLP-1 analogue) and PKA levels analyzed. PKA level was normalized with GAPDH and mean \pm SD shown from three independent experiments. ${ }^{*} p<0.05$ was marked in the column significantly different to the untreated control.

\subsection{Single-Dose Hypoglycemic Effect of Natural Compounds}

To understand the regulating effect of selected natural compounds on blood sugar in TII DM patients, diabetic DIO mice were administered HCD, quercetin, berberine, and sitagliptin (DPP4i) combined with $4 \mathrm{~g} / \mathrm{kg}$ glucose to measure blood sugar changes. After converting blood sugar levels into the area under the curve (AUC), all treated groups showed a lower AUC than the DIO mice alone, which meant lowered blood sugar levels during the same testing period (Figure 5). Furthermore, the AUC of natural compound treated groups were not significantly different with normal mice. This result indicated that the tested natural compounds could safely lower blood glucose level but not cause a risk of hypoglycemia. When the above results were taken together, HCD could decrease blood sugar level in diabetic mice without increasing the risk of hypoglycemia. For further validation, the long-term control ability of HCD was tested.

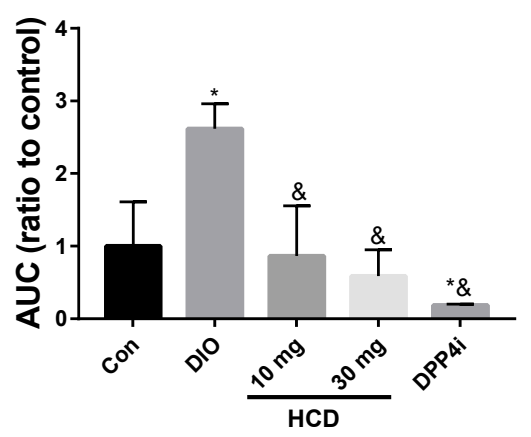

Figure 5. Insulin tolerance of DIO mice after selected natural compound gavaging. DIO mice were fed with HCD and Sitagliptin (DPP4i) and then insulin tolerance measured through OGTT. Results were shown as mean \pm SEM from 6 individuals $* p<0.05$ represented as significantly different compared with normal mice (Con), and \& $p<0.05$ represented as significantly different from DIO mice.

\subsection{Long-Term Blood Sugar Administration of Natural Compounds}

Blood sugar control effects from natural compounds could be observed with two markers: AUC of the OGTT test and $\mathrm{HbA1c} \%$. After 28 days of natural compound feeding, AUC of DIO mice significantly ameliorated to be lower than the controls (non-induced) (Figure 6A). Compared with before and after sitagliptin (DPP4i), this result of HCD demonstrated that the hypoglycemic potential was similar to sitagliptin (DPP4i). However, HbA1c levels of HCD treatment were not different to 
these before treatment (Figure 6B), which hinders the reduction of advanced glycated end products in HCD and might be due to short duration of the compound and the cause of fluctuation of blood glucose. The next experiment was to evaluate the regulating efficacy of HCD in diabetic complications.

(A) OGTT

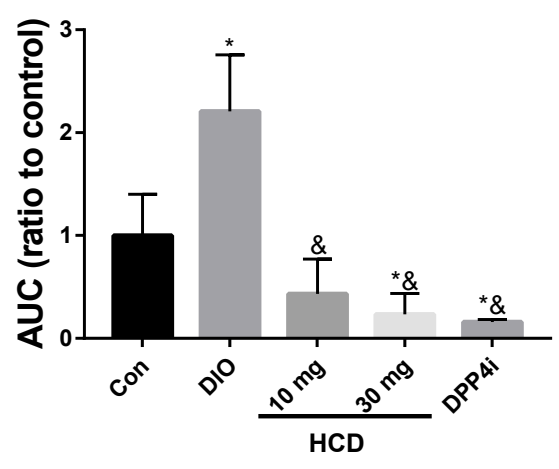

(B) HbA1c

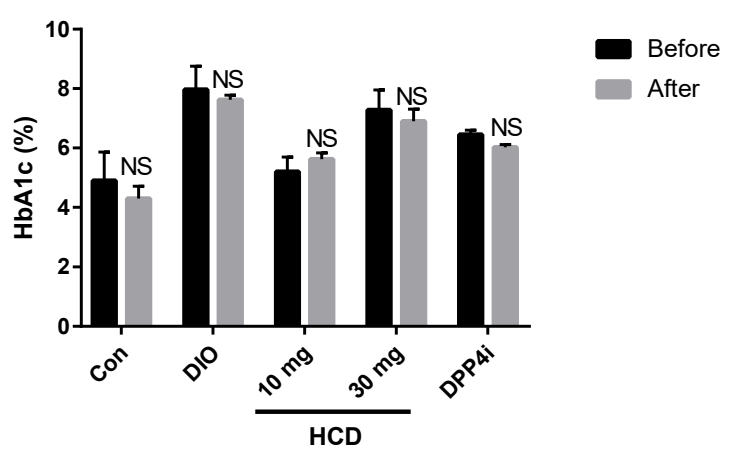

Figure 6. Insulin tolerance and glycated hemoglobulin $(\mathrm{HbA} 1 \mathrm{c})$ levels after long-term administration of natural compounds. DIO mice were fed with natural compounds for 5 weeks and insulin tolerance measured through (A) OGTT and (B) HbA1c levels. All results were mean \pm SD from 6 individuals. $* p<0.05$ meant significantly different as compared with Con $(\mathbf{A})$ or before treatment $(\mathbf{B})$, and ${ }^{*} p<0.05$ represented significantly different from DIO mice.

\subsection{Dyslipidemia Reducing Effect in Long-Term Administration}

In the pathology of diabetes, dyslipidemia has been well identified. In TII DM, dyslipidemia, especially hyperlipidemia and hypercholesterolemia, was not only induced by diabetes but also by a high fat diet [20]. Therefore, control of blood lipids and cholesterol could be a marker for diabetic control. After four weeks of treatment, total serum triglyceride (TG) and cholesterol were analyzed. When compared before and after the given natural compounds, serum TG in a high dose of HCD $(30 \mathrm{mg} / \mathrm{kg}$ ) treatment was significantly attenuated (Figure 7A). However, total cholesterol for each treatment was not different (Figure 7B).

(A) TG

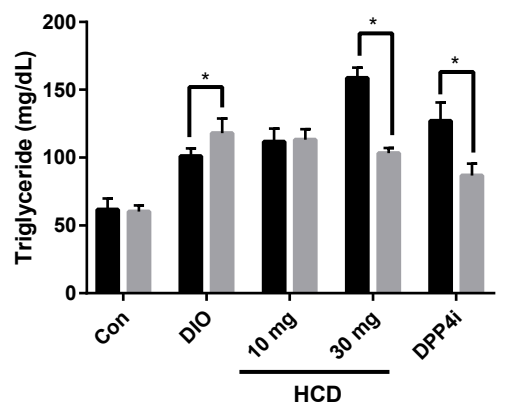

(B) $\mathrm{CHO}$

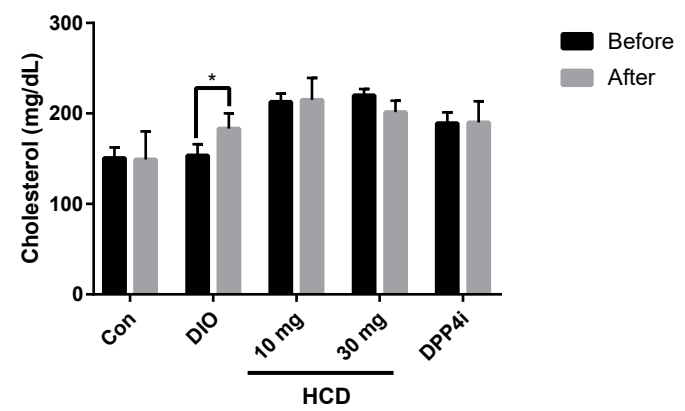

Figure 7. Alteration of serum lipid levels after selected natural compounds' administration. HCD and sitagliptin (DPP4i) were fed to DIO mice for 5 weeks, respectively, and serum monitored (A) triglyceride and (B) cholesterol after treatment. All results were mean \pm SD from 6 individuals. ${ }^{*} p<0.05$ meant significantly different as compared with that before treatment.

\subsection{Toxicity in Long-Term Administration}

Although natural compounds were considered as having lower toxicity and less adverse effects than conventional agents, unsuspected toxicity in long-term administration still needs to be considered [21]. In this study, the body weight and GOT/GPT were used to monitor the overall and hepatotoxicity in HCD administration. When compared with untreated DIO mice, the body weight of 
HCD treatments was not significantly changed (Figure 8A). Furthermore, the GPT level after HCD treatment was significantly lower than before. These results implied that overall and hepatotoxicity were not observed (Figure 8B). Additionally, the GOT level of HCD treatment did not change when GPT decreased, indicating that liver inflammation might be ameliorated (Figure 8C). HCD exhibited hypoglycemic efficacy for short-term administration (not long-term), which implied the emergent use of HCD in rapid blood sugar control.
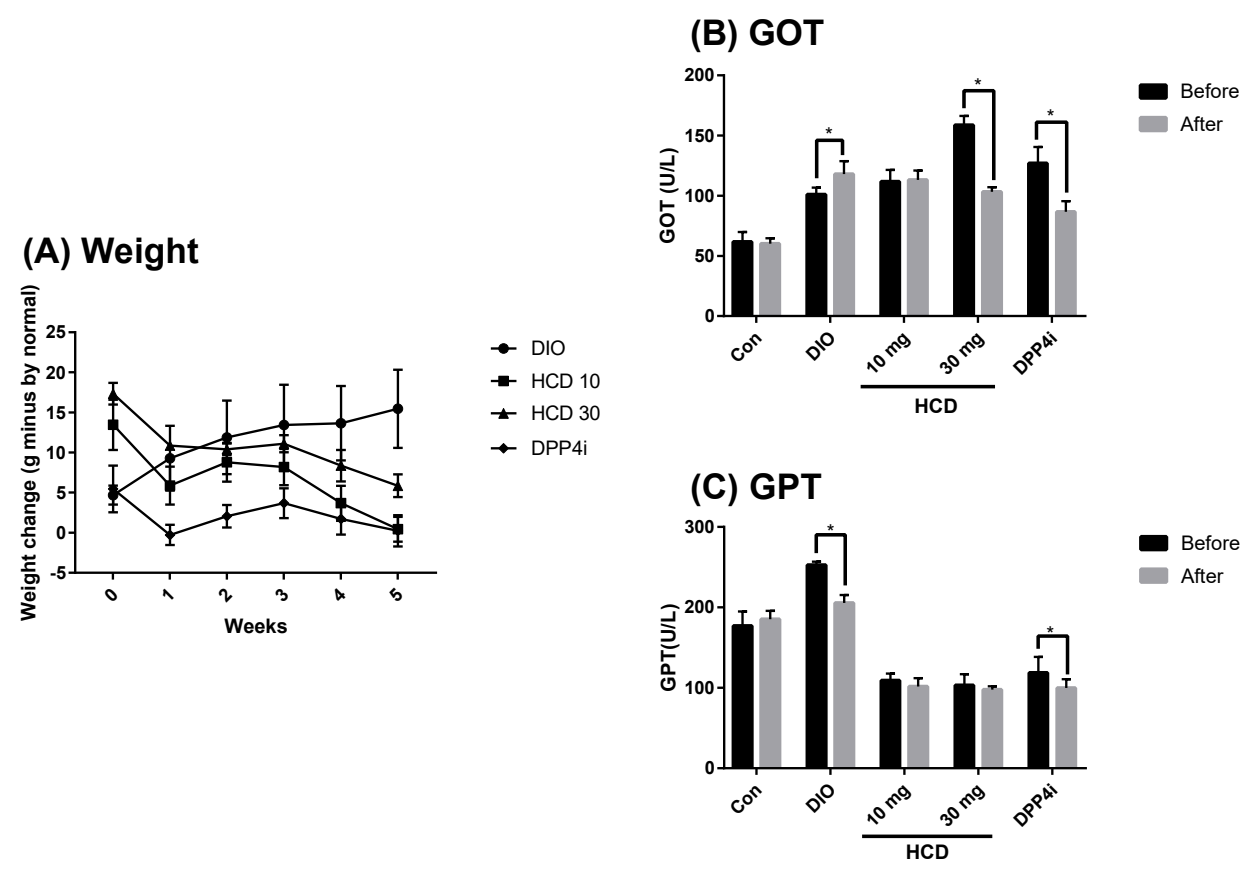

Figure 8. Estimating overall- and hepato-toxicity of selected natural compounds during long-term administration. Overall and hepatotoxicity in DIO mice fed with HCD or sitagliptin (DPP4i) for 5 weeks were monitored by (A) Body weight, (B) GOT, and (C) GPT. All results were mean \pm SD from 6 individuals. ${ }^{*} p<0.05$ meant significantly different as compared to that before treatment.

\section{Discussion}

To validate the DPP-4 inhibitory potency of HCD, berberine, rutin, and quercetin selected previously by in silico, the results of direct enzymatic alteration of selected natural compounds against DPP-4 showed inhibition effects in all compounds, with HCD being the most potent compound. In in vitro cellular assays, DPP-4-related activity and signaling change could also be observed in HCD treated in Caco-2 cells, LPS-activated ERK phosphorylation in myocytes, or PKA up-regulation in pancreatic cells. Using DIO-induced diabetic mice, HCD could decrease postprandial blood sugar regardless of single dose or long-term administration. However, HCD could not diminish $\mathrm{HbA1c}$ levels after long-term administration, which emphasizes HCD as not being able to decrease the highest level of postprandial blood sugar levels and eliminate blood sugar fast enough. Interestingly, HCD ameliorated DIO-induced hypertriglyceridemia and GOT activity after long-term administration. When taken together, HCD natural DPP-4 inhibitor selected from molecular docking is a compelling DPP-4 inhibitor and antidiabetic candidate.

After molecular docking, the binding pattern of selected natural compounds and DPP-4 were diagramed. Rutin formed three $\mathrm{H}$-bonds at $\mathrm{Glu}^{158}$, $\mathrm{Arg}^{252}$, and $\mathrm{Cys}^{257}$; quercetin formed four H-bonds or $\pi-\pi$ interactions at $\mathrm{Arg}^{125}, \mathrm{His}^{126}, \mathrm{Glu}^{158}$, and Phe ${ }^{253}$; HCD formed two H-bonds at Arg ${ }^{125}$ and Arg 186 ; and berberine only formed one H-bond at Lys ${ }^{55}$ (Figure S1). However, comparing bond formation from simulation and in vitro enzymatic assay, bond formation seemed not to be related to the inhibitory activities, whereas HCD exhibited the highest inhibitory activity but did not form the most bonds in simulation (Figure 1). Besides, HCD and berberine interacted with $\mathrm{Tyr}^{662}$ and $\mathrm{Tyr}^{666}$ 
around the binding site and showed stronger inhibitory activities than those of rutin and quercetin. This impact could also be evaluated from the binding simulation of curcumin in a previous study [14]. This result speculated that interaction with $\mathrm{Tyr}^{662}$ and $\mathrm{Tyr}^{666}$ might be more important than others.

Screening DPP-4 inhibitors for treating diabetes is a recently developing field (since 2006), when a study reported that DPP-4 might regulate insulin sensitivity via degradation of GLP-1 [22]. Up to now, few natural DPP-4 inhibitors have been reported [23] From plant origin, DPP-4 inhibitory activities of kaempferol and derivatives, linustatins, chrysin, stigmasterol, emodin, lupeol, mangiferin, vitisins, and soybean hydrolysates were all validated via direct enzymatic assay and in vivo hypoglycemic analysis [24-31]. Moreover, the methanolic extracts of Ficus benghalensis, Syzigium cumini, Ocimum sanctum, and Eucalyptus sp. were also highlighted as sources of DPP-4 inhibitors [32,33]. From searching in animals, protein hydrolysates from milk and barbels with sequences of Leu-Pro-Val-Pro-Gln, Ile-Pro-Met, Trp-Ser-Gly, and Phe-Ser-Asp, elicited modifying activity for DPP-4 [34,35]. These reports emphasized the importance of searching for potent DPP-4 inhibitors from natural sources. Our study proposed HCD as a new DPP-4 inhibitor and further validated tits hypoglycemic efficacy in diabetic mice, which could be a new alternative hope for treating diabetes.

Polyathia longifolia is a febrifuge and indigestion drug in traditional Indian medication [36]. Recently, P. longifolia has been proven to have various biological activities such as anticancer, antimicrobial, immune-modulative, anti-hypertensive, and anti-ulcer [36]. Diterpene 16-hydroxycleroda-3,13-dien-15,16-olide (HCD) was isolated from P. longifolia bark with biological functions that pointed to two major phases: immunomodulation and anti-tumor [37]. Microglia could induce neuron cell death while it was stimulated by liposaccharide. HCD could down-regulate the expression of inflammatory-related signaling pathways including iNOS, COX-2, NF-kB, IкB, and TNF- $\alpha$; and resulted in avoiding neuron cell death [38]. For the antitumor effect, HCD could activate apoptotic cell death in chronic myelogenous leukemia cells [39], renal carcinoma cells [40], autophagic cell death in oral squamous cell carcinoma [41], and glioma cells via ROS burst [42]. For breast cancer treatment, HCD pretreatment could potentiate tamoxifen tumoricidal efficacy via down-regulating anti-apoptotic signaling [43]. In renal cell carcinoma cells, HCD induced anoikis by decreasing focal adhesion kinase-related signaling, which blocks tumor cell invasion and turns into apoptosis [44]. A previous study reported the hypoglycemic activity of HCD via inhibiting $\alpha$-amylase $/ \alpha$-glucosidase activity by the in-silico method $[45,46]$. This study afterwards elicited the hypoglycemic efficacy of HCD along with DPP-4 inhibition. Generally, the bioavailability of HCD via oral administration was low. Nanoparticle-encapsulation like mesoporous silica nanoparticles could significantly enhance the bioactivity of HCD in antidiabetic and antitumor activity [47,48].

In our previous study, rutin, quercetin, and berberine showed DPP-4 inhibitory potency while docking with DPP-4 [14]. In the literature, the hypoglycemic effect of berberine has been investigated for many years. Berberine could activate AMP-activated protein kinase (AMPK), nuclear factor erythroid-2-related factor-2 (Nrf2), and NF- $\mathrm{KB}$ signaling pathway and result in elevating insulin sensitivity [49]. Also, berberine could increase insulin secretion in vivo [49]. To the best of our knowledge, the hypoglycemic mechanism of rutin has been proposed in four directions: 1. elevation of glycogenesis and reducing gluconeogenesis; 2. promoting glucose uptake in myocytes by inducing translocation of glucose transporter 4; 3. reducing glucose absorption in the intestine; and 4. enhancing Langerhans islet cell activity and increasing insulin secretion [50]. For quercetin, the best-known hypoglycemic mechanism is $\alpha$-amylase/ $\alpha$-glucosidase inhibition $[45,46,51]$. In this study, three natural-DPP-4 inhibitory candidates were investigated in an enzymatic and in vitro cellular assay, but their inhibitory potency was lower than for HCD. Additionally, other hypoglycemic mechanisms such as attenuating urine glucose reabsorption are worth further attention for testing. 


\section{Materials and Methods}

\subsection{Natural Compounds and Reagents}

The molecular docking of natural compounds against DPP-4 was described in a previous study [14]. Selected natural compounds were purified by Yi-Chen Chia (Department of Food Science and Technology, Tajen University, Pingtung, Taiwan). Reagents and mediums for cell culture were obtained from Thermo-Fisher Inc. (Waltham, MA, USA). General chemicals were purchased from Sigma-Aldrich (Merck KGaA, Darmstadt, Hesse, Germany).

\subsection{Western Blotting}

Cells were collected and lysed in ice-cold RIPA buffer $(150 \mathrm{mM} \mathrm{NaCl}, 1.0 \% \mathrm{NP}-40,0.5 \%$ sodium deoxycholate, $0.1 \%$ sodium dodecyl sulphate (SDS), $50 \mathrm{mM}$ Tris- $\mathrm{HCl}$ at $\mathrm{pH}$ 8.0) with protein inhibitor cocktail (Roche Holding AG, Basel, Kanton Basel-Stadt, Switzerland) at $4{ }^{\circ} \mathrm{C}$ for $60 \mathrm{~min}$. Cell debris was discarded by centrifugation at $12,000 \mathrm{~g}$ for $30 \mathrm{~min}$ at $4{ }^{\circ} \mathrm{C}$, and protein concentration in suspension was quantified using a Bradford protein assay (Bio-Rad, Hercules, CA, USA). A total of $30 \mu g$ of proteins was separated using SDS-PAGE and, subsequently, transferred to a PVDF membrane (PERKin Elmer Life Sciences, Boston, MA, USA). Desired proteins were stained with appropriated 1st antibodies and HRP-conjugated 2nd antibodies. After staining, whole membranes were immersed in ECL reagent (Bio-Rad) and chemiluminescent intensity detected by a LAS-3000 imager (Fujifilm, Minato, Tokyo, Japan). Chemiluminescence of each protein was normalized with chemiluminescence of GAPDH, and the protein levels were presented as the intensity ratio to the untreated controls.

\subsection{In Vitro DPP-4 Inhibitory Assay}

\subsubsection{Cell Culture}

Mouse myoblast cells C2C12, rat pancreas tumor cells AR42J, and human colorectal adenocarcinoma cells Caco-2 were obtained from the Bioresource Collection and Research Center (BCRC, Hsinchu, Taiwan) and American Type Culture Collection (Manassas, VA, USA), respectively. Cells were grown in high-glucose Dulbecco's Modified Eagle's Medium supplied with 10\% (C2C12) and 20\% (AR42J and Caco-2) fetal bovine serum plus 1\% penicillin/streptomycin and the medium were changed every 2 days. Cells were maintained under $37{ }^{\circ} \mathrm{C}, 5 \% \mathrm{CO}_{2}$ in water-jacket incubator (Thermo-Fisher) and detached by $0.25 \%$ trypsin/EDTA while reached $80 \%$ confluence. All experiments were carried out within 10 passages for controlling uniformity and consistency.

\subsubsection{Enzymatic Inhibition Assay}

In vitro enzymatic assay of DPP-4 was carried out by Enzo ${ }^{\circledR}$ DPP-4/CD26 Assay Kit for Biological Samples (Enzo Life Sciences, Inc., Farmingdale, NY, USA) and following the protocol in the manual. Briefly, $50 \mu \mathrm{L}$ of assay buffer, $20 \mu \mathrm{L}$ of DPP-4, and $20 \mu \mathrm{L}$ of test samples (natural compounds, sitagliptin, and hemifumarate) were sequentially mixed in 96-well plate, respectively. After 30 min of incubation, $10 \mu \mathrm{L}$ of enzyme substrate (H-Gly-Pro-pNA) was added and the optical intensity measured at $405 \mathrm{~nm}$. The DPP-4 activity treated with hemifumarate was set as $100 \%$, the tested samples were measured with hemifumarate and the data presented as the ratio to hemifumarate.

\subsubsection{Cellular DPP-4 Inhibition Assay}

In vitro cellular DPP-4 inhibition assay could be divided into 3 assays: ERK phosphorylation inhibition in LPS-stimulated muscle cells, PKA activation in incretin-induced pancreatic cells, and expression inhibition in Caco-2 cells. The inhibition of DPP-4 expression in Caco-2 cells was performed by Western blotting. Caco-2 cells were inoculated into a 12-well plate followed by natural compounds' treatment for 12, 24, and $36 \mathrm{~h}$, respectively. After treatments, DPP-4 levels and PKA activating inhibition were determined by Western blotting. A number of $1 \times 10^{5}$ cells/wells of AR42J cells 
was seeded into a 12-well plate and incubated overnight for confluence. Then, cells were incubated with 1 nM of GLP-1, exendin-4 (Ex-4), natural compounds with GLP-1, or natural compounds with Ex-4 for 48 h, respectively. Finally, PKA levels within AR42J were determined by Western blotting. LPS-induced ERK-phosphorylation followed the above protocol with slight modification. A number of $5 \times 10^{4}$ cells/wells of C2C12 was used in this study. After incubating overnight, $10 \mathrm{ng} / \mathrm{mL}$ of LPS was added for 10 and $30 \mathrm{~min}$, respectively, followed by culturing with natural compounds for $12 \mathrm{~h}$. Phosphorylated-ERK was assayed by Western blotting.

\subsection{In Vivo Animal Test}

\subsubsection{Animals and Obese Induction}

Six-week-old male ICR mice were obtained from the National Laboratory Animal Center (Taipei, Taiwan) and kept in controlled environmental conditions at room temperature $\left(22 \pm 2{ }^{\circ} \mathrm{C}\right)$ and with humidity $(50 \pm 10 \%)$. The $12 \mathrm{~h}$ light/dark cycle were maintained throughout the study. Mice had free access to food and water and were maintained on a standard laboratory diet. Animal experiments were approved by the National Dong-Hwa University Animal Ethics Committee (approval number 001 at 29 December 2014) and were used according to the "Guide for the Care and Use of Laboratory Animals" of National Dong-Hwa University. Diet-induced obese (DIO) mice were treated with a high-fat and high-fructose diet. ICR mice were divided into 2 groups: DIO mice were fed with high-fat (commercial diet supplied with $150 \mathrm{~g} / \mathrm{kg}$ lard) and high fructose $(60 \% \mathrm{w} / \mathrm{v})$ diet for 14 weeks; control group was fed with a normal diet. At week 10, mice were treated with an oral glucose tolerance test (OGTT) and an insulin intolerance test for the determination of DM type. If the blood sugar level at $120 \mathrm{~min}$ after gavaging was higher than $200 \mathrm{mg} / \mathrm{dL}$, mice were categorized as insulin intolerant. When the insulin-intolerant mice failed the insulin intolerance test, the mice could be diagnosed as TII DM mice.

\subsubsection{Oral Glucose Tolerance Test (OGTT) and Insulin Intolerance Test}

To check diabetic symptoms in DIO mice, we used postprandial blood sugar level and insulin tolerance. Before operating OGTT, mice were fasted for $12 \mathrm{~h}$, blood was sampled from the tail vein, and the blood sugar level was tested using an Accu-Chek blood sugar analyzer (Roche Holding AG) prior to oral gavage (p.o.) with $4 \mathrm{~g} / \mathrm{kg}$ glucose solution. After p.o., blood sugar was continuously measured at 30,60,90, and 120 min after gavaging. All data in each group were collected and plotted with gavaging time to calculate the area under curve (AUC). Insulin intolerance testing used the same protocol with OGTT. After p.o. glucose, mice were immediately intraperitoneal (i.p.) injected $0.8 \mathrm{IU} / \mathrm{kg}$ Bwt insulin solution (Novo Nordisk A/S, Kalundborg, Denmark).

\subsubsection{Single-Dose Hypoglycemic Efficacy}

To determine hypoglycemic efficacy in a single dose, OGTT in DIO mice was employed. OGTT was tested on DIO mice with the same protocol as in the previous section. After p.o. glucose, mice were immediately treated p.o. with natural compounds and blood sugar levels tested.

\subsubsection{Long Term Administration}

Long term administration was carried out in DIO mice. Diabetic DIO mice were allotted to treated groups for 6 mice and treated p.o. with natural compounds once per 7 days for 28 days. Body weight was measured every 7 days. At the end of treatment, OGTT was carried out to check insulin tolerance.

\subsubsection{Blood Biochemical Detection}

At the beginning and end of treatment, $500 \mu \mathrm{L}$ of whole blood was collected by piercing the cheek and separating into 2 parts: $100 \mu \mathrm{L}$ mixed with $3.2 \%$ sodium citrate to measure glycated hemoglobulin (HbA1c) immediately; $400 \mu \mathrm{L}$ incubated at room temperature for coagulation and then centrifuging at 
$4000 \mathrm{rpm}$ for $10 \mathrm{~min}$ to collect serum using total triglyceride (TG), total cholesterol (CHO), glutamate oxaloacetate transaminase (GOT), and glutamate pyruvate transaminase (GPT) tested by an automatic analyzer (ARTAX Menarini Diagnostics, Florence, Italy).

\subsection{Statistical Analysis}

All data were expressed as means with standard deviations (mean $\pm \mathrm{SD}$ ) and the data were analyzed using one-way ANOVA with a Dunnett's test. The level of statistical significance was set at $p<0.05$. All statistical procedures were performed with GraphPad Prism version 7.0 (GraphPad Software, Inc., La Jolla, CA, USA).

\section{Conclusions}

When taken together, HCD is first evident in showing DPP-4 inhibitory activity and blood sugar lowering efficacy in short-term and long-term administration. Combining with $\alpha$-amylase / $\alpha$-glucosidase, inhibition potency having been previously demonstrated, HCD poses a high potential for becoming an antidiabetic drug candidate. The antidiabetic potency of HCD has been under-estimated in research and it worthwhile seeking the impact of a clinical trial.

Supplementary Materials: Supplementary materials can be found at http:/ /www.mdpi.com/1422-0067/20/3/ $530 /$ s1.

Author Contributions: Conceptualization, C.-F.W. and Y.-S.F.; methodology, P.-K.H.; software, S.-R.L.; validation, S.-R.L. and J.R.; formal analysis, P.-K.H. and S.-R.L.; investigation, P.-K.H.; resources, C.-F.W.; writing-original draft preparation, S.-R.L. and J.R.; writing-review and editing, C.-F.W.; project administration, C.-F.W.; funding acquisition, C.-F.W.

Funding: This research was funded by the Ministry of Science and Technology, grant number 104-2320-B-259-001-MY3 (C.F.W.).

Conflicts of Interest: The authors declare no conflict of interest.

\section{Abbreviations}

$\begin{array}{ll}\text { AUC } & \text { Area under curve } \\ \text { CHO } & \text { Total cholesterol } \\ \text { DIO } & \text { Diet-induced obese } \\ \text { DPP-4 } & \text { Dipeptidyl peptidase 4 } \\ \text { ECL } & \text { Enhanced chemiluminescence } \\ \text { ERK } & \text { Extracellular signal-regulated kinases } \\ \text { GAPDH } & \text { Glyceraldehyde 3-phosphate dehydrogenase } \\ \text { GLP-1 } & \text { Glucagon like peptide 1 } \\ \text { GOT } & \text { Glutamic oxaloacetic transaminase } \\ \text { GPT } & \text { Glutamic-pyruvic transaminase } \\ \text { HbA1c } & \text { Glycated hemoglobin } \\ \text { HCD } & \text { 16-hydroxycleroda-3,13-dien-15,16-olide } \\ \text { HRP } & \text { Horseradish peroxidase } \\ \text { LPS } & \text { Lipopolysaccharide } \\ \text { OGTT } & \text { Oral glucose tolerance test } \\ \text { PKA } & \text { Protein kinase A } \\ \text { PVDF } & \text { Polyvinylidene difluoride } \\ \text { TG } & \text { Triglyceride } \\ \text { TII DM } & \text { Type 2 diabetes mellitus }\end{array}$

\section{References}

1. Cho, N.H.; Shaw, J.E.; Karuranga, S.; Huang, Y.; da Rocha Fernandes, J.D.; Ohlrogge, A.W.; Malanda, B. Idf diabetes atlas: Global estimates of diabetes prevalence for 2017 and projections for 2045. Diabetes Res. Clin. Pract. 2018, 138, 271-281. [CrossRef] [PubMed] 
2. DALYs, G.B.D.; Collaborators, H. Global, regional, and national disability-adjusted life-years (DALYs) for 333 diseases and injuries and healthy life expectancy (HALE) for 195 countries and territories, 1990-2016: A systematic analysis for the global burden of disease study 2016. Lancet 2017, 390, 1260-1344.

3. American Diabetes Association. 8. Pharmacologic approaches to glycemic treatment: Standards of medical care in diabetes-2018. Diabetes Care 2018, 41, S73-S85. [CrossRef] [PubMed]

4. Barnett, A. DPP-4 inhibitors and their potential role in the management of type 2 diabetes. Int. J. Clin. Pract. 2006, 60, 1454-1470. [CrossRef] [PubMed]

5. Lambeir, A.M.; Durinx, C.; Scharpe, S.; De Meester, I. Dipeptidyl-peptidase iv from bench to bedside: An update on structural properties, functions, and clinical aspects of the enzyme DPP IV. Crit. Rev. Clin. Lab. Sci. 2003, 40, 209-294. [CrossRef] [PubMed]

6. Yu, D.M.; Slaitini, L.; Gysbers, V.; Riekhoff, A.G.; Kahne, T.; Knott, H.M.; De Meester, I.; Abbott, C.A.; McCaughan, G.W.; Gorrell, M.D. Soluble CD26/dipeptidyl peptidase IV enhances human lymphocyte proliferation in vitro independent of dipeptidyl peptidase enzyme activity and adenosine deaminase binding. Scand. J. Immunol. 2011, 73, 102-111. [CrossRef] [PubMed]

7. Casrouge, A.; Sauer, A.V.; Barreira da Silva, R.; Tejera-Alhambra, M.; Sanchez-Ramon, S.; ICAReB; Cancrini, C.; Ingersoll, M.A.; Aiuti, A.; Albert, M.L. Lymphocytes are a major source of circulating soluble dipeptidyl peptidase 4. Clin. Exp. Immunol. 2018, 194, 166-179. [CrossRef]

8. Uhlen, M.; Fagerberg, L.; Hallstrom, B.M.; Lindskog, C.; Oksvold, P.; Mardinoglu, A.; Sivertsson, A.; Kampf, C.; Sjostedt, E.; Asplund, A.; et al. Proteomics. Tissue-based map of the human proteome. Science 2015, 347, 1260419. [CrossRef]

9. Rohrborn, D.; Wronkowitz, N.; Eckel, J. DPP4 in diabetes. Front. Immunol. 2015, 6, 386. [CrossRef]

10. Al Tulaihi, B.; Alhabib, S. Uncertainties around incretin-based therapies: A literature review. Saudi Pharm. J. 2017, 25, 1-7. [CrossRef]

11. Lin, S.R.; Fu, Y.S.; Tsai, M.J.; Cheng, H.; Weng, C.F. Natural compounds from herbs that can potentially execute as autophagy inducers for cancer therapy. Int. J. Mol. Sci. 2017, 18, 1412. [CrossRef] [PubMed]

12. Meng, X.Y.; Zhang, H.X.; Mezei, M.; Cui, M. Molecular docking: A powerful approach for structure-based drug discovery. Curr. Comput. Aided Drug Des. 2011, 7, 146-157. [CrossRef] [PubMed]

13. Rognan, D. The impact of in silico screening in the discovery of novel and safer drug candidates. Pharmacol. Ther. 2017, 175, 47-66. [CrossRef] [PubMed]

14. Huang, P.K.; Lin, S.R.; Chang, C.H.; Tsai, M.J.; Lee, D.N.; Weng, C.F. Natural phenolic compounds potentiate hypoglycemia via inhibition of dipeptidyl peptidase IV. Sci. Rep. 2018. under press.

15. Darmoul, D.; Lacasa, M.; Baricault, L.; Marguet, D.; Sapin, C.; Trotot, P.; Barbat, A.; Trugnan, G. Dipeptidyl peptidase IV (CD 26) gene expression in enterocyte-like colon cancer cell lines HT-29 and Caco-2. Cloning of the complete human coding sequence and changes of dipeptidyl peptidase IV mRNA levels during cell differentiation. J. Biol. Chem. 1992, 267, 4824-4833. [PubMed]

16. Hasan, A.A.; Hocher, B. Role of soluble and membrane-bound dipeptidyl peptidase- 4 in diabetic nephropathy. J. Mol. Endocrinol. 2017, 59, R1-R10. [CrossRef] [PubMed]

17. Wronkowitz, N.; Gorgens, S.W.; Romacho, T.; Villalobos, L.A.; Sanchez-Ferrer, C.F.; Peiro, C.; Sell, H.; Eckel, J. Soluble DPP4 induces inflammation and proliferation of human smooth muscle cells via protease-activated receptor 2. Biochim. Biophys. Acta 2014, 1842, 1613-1621. [CrossRef]

18. Omar, B.A.; Liehua, L.; Yamada, Y.; Seino, Y.; Marchetti, P.; Ahren, B. Dipeptidyl peptidase 4 (DPP-4) is expressed in mouse and human islets and its activity is decreased in human islets from individuals with type 2 diabetes. Diabetologia 2014, 57, 1876-1883. [CrossRef]

19. Dalle, S.; Burcelin, R.; Gourdy, P. Specific actions of GLP-1 receptor agonists and DPP4 inhibitors for the treatment of pancreatic beta-cell impairments in type 2 diabetes. Cell. Signal. 2013, 25, 570-579. [CrossRef]

20. Schofield, J.D.; Liu, Y.; Rao-Balakrishna, P.; Malik, R.A.; Soran, H. Diabetes dyslipidemia. Diabetes Ther. 2016, 7, 203-219. [CrossRef]

21. Khatoon, A.; Rashid, I.; Shaikh, S.; Rizvi, S.M.D.; Shakil, S.; Pathak, N.; Mir, S.S.; Ahmad, K.; Hussain, T.; Srivastava, P. Adncd: A compendious database on anti-diabetic natural compounds focusing on mechanism of action. 3 Biotech 2018, 8, 361. [CrossRef] [PubMed]

22. Drucker, D.J.; Nauck, M.A. The incretin system: Glucagon-like peptide-1 receptor agonists and dipeptidyl peptidase-4 inhibitors in type 2 diabetes. Lancet 2006, 368, 1696-1705. [CrossRef] 
23. Wang, H.J.; Chiang, B.H. Anti-diabetic effect of a traditional Chinese medicine formula. Food Funct. 2012, 3, 1161-1169. [CrossRef]

24. Kalhotra, P.; Chittepu, V.; Osorio-Revilla, G.; Gallardo-Velazquez, T. Structure(-)activity relationship and molecular docking of natural product library reveal chrysin as a novel dipeptidyl peptidase-4 (DPP-4) inhibitor: An integrated in silico and in vitro study. Molecules 2018, 23, 1368. [CrossRef]

25. Yang, Q.Y.; Song, L.; Zhang, J.F.; Shen, Z.F.; Liu, Q.; Liu, S.N.; Zheng, W.S.; Yao, C.S. Cyanogenetic glycosides and simple glycosides from the linseed meal. Fitoterapia 2015, 106, 78-83. [CrossRef] [PubMed]

26. Zhao, B.T.; Le, D.D.; Nguyen, P.H.; Ali, M.Y.; Choi, J.S.; Min, B.S.; Shin, H.M.; Rhee, H.I.; Woo, M.H. PTB1B, $\alpha$-glucosidase, and DPP-IV inhibitory effects for chromene derivatives from the leaves of Smilax china $\mathrm{L}$. Chem. Biol. Interact. 2016, 253, 27-37. [CrossRef]

27. Lammi, C.; Bollati, C.; Ferruzza, S.; Ranaldi, G.; Sambuy, Y.; Arnoldi, A. Soybean- and lupin-derived peptides inhibit DPP-IV activity on in situ human intestinal Caco-2 cells and ex vivo human serum. Nutrients 2018, 10, 1082. [CrossRef]

28. Lin, Y.S.; Chen, C.R.; Wu, W.H.; Wen, C.L.; Chang, C.I.; Hou, W.C. Anti-alpha-glucosidase and anti-dipeptidyl peptidase-IV activities of extracts and purified compounds from Vitis thunbergii var. Taiwaniana. J. Agric. Food Chem. 2015, 63, 6393-6401. [CrossRef]

29. Saleem, S.; Jafri, L.; ul Haq, I.; Chang, L.C.; Calderwood, D.; Green, B.D.; Mirza, B. Plants Fagonia cretica L. and Hedera nepalensis $\mathrm{K}$. Koch contain natural compounds with potent dipeptidyl peptidase-4 (DPP-4) inhibitory activity. J. Ethnopharmacol. 2014, 156, 26-32. [CrossRef]

30. Suman, R.K.; Mohanty, I.R.; Maheshwari, U.; Borde, M.K.; Deshmukh, Y.A. Natural dipeptidyl peptidase-iv inhibitor mangiferin mitigates diabetes- and metabolic syndrome-induced changes in experimental rats. Diabetes Metab. Syndr. Obes. 2016, 9, 261-272. [CrossRef]

31. Wang, Z.; Yang, L.; Fan, H.; Wu, P.; Zhang, F.; Zhang, C.; Liu, W.; Li, M. Screening of a natural compound library identifies emodin, a natural compound from Rheum palmatum linn. that inhibits DPP4. Peer J. 2017, 5, e3283. [CrossRef] [PubMed]

32. De, B.; Bhandari, K.; Singla, R.K.; Katakam, P.; Samanta, T.; Kushwaha, D.K.; Gundamaraju, R.; Mitra, A. Chemometrics optimized extraction procedures, phytosynergistic blending and in vitro screening of natural enzyme inhibitors amongst leaves of tulsi, banyan and jamun. Pharmacogn. Mag. 2015, 11, S522-S532. [PubMed]

33. Dey, B.; Mitra, A.; Katakam, P.; Singla, R.K. Exploration of natural enzyme inhibitors with hypoglycemic potentials amongst Eucalyptus spp. by in vitro assays. World J. Diabetes 2014, 5, 209-218. [CrossRef] [PubMed]

34. Nongonierma, A.B.; FitzGerald, R.J. Structure activity relationship modelling of milk protein-derived peptides with dipeptidyl peptidase IV (DPP-IV) inhibitory activity. Peptides 2016, 79, 1-7. [CrossRef] [PubMed]

35. Sila, A.; Alvarez, O.M.; Haddar, A.; Frikha, F.; Dhulster, P.; Nedjar-Arroume, N.; Bougatef, A. Purification, identification and structural modelling of DPP-IV inhibiting peptides from barbel protein hydrolysate. J. Chromatogr. B 2016, 1008, 260-269. [CrossRef] [PubMed]

36. Katkar, K.V.; Suthar, A.C.; Chauhan, V.S. The chemistry, pharmacologic, and therapeutic applications of Polyalthia longifolia. Pharmacogn. Rev. 2010, 4, 62-68. [PubMed]

37. Wu, T.H.; Cheng, Y.Y.; Chen, C.J.; Ng, L.T.; Chou, L.C.; Huang, L.J.; Chen, Y.H.; Kuo, S.C.; El-Shazly, M.; $\mathrm{Wu}$, Y.C.; et al. Three new clerodane diterpenes from Polyalthia longifolia var. Pendula. Molecules 2014, 19, 2049-2060. [CrossRef] [PubMed]

38. Shih, Y.T.; Hsu, Y.Y.; Chang, F.R.; Wu, Y.C.; Lo, Y.C. 6-hydroxycleroda-3,13-dien-15,16-olide protects neuronal cells from lipopolysaccharide-induced neurotoxicity through the inhibition of microglia-mediated inflammation. Planta Med. 2010, 76, 120-127. [CrossRef] [PubMed]

39. Lin, Y.H.; Lee, C.C.; Chang, F.R.; Chang, W.H.; Wu, Y.C.; Chang, J.G. 16-hydroxycleroda-3,13-dien-15,16-olide regulates the expression of histone-modifying enzymes PRC2 complex and induces apoptosis in CML K562 cells. Life Sci. 2011, 89, 886-895. [CrossRef] [PubMed]

40. Liu, C.; Lee, W.C.; Huang, B.M.; Chia, Y.C.; Chen, Y.C.; Chen, Y.C. 16-hydroxycleroda-3, 13-dien-15, 16-olide inhibits the proliferation and induces mitochondrial-dependent apoptosis through Akt, mTOR, and MEK-ERK pathways in human renal carcinoma cells. Phytomedicine 2017, 36, 95-107. [CrossRef] [PubMed] 
41. Cheng, M.F.; Lin, S.R.; Tseng, F.J.; Huang, Y.C.; Tsai, M.J.; Fu, Y.S.; Weng, C.F. The autophagic inhibition oral squamous cell carcinoma cancer growth of 16-hydroxy-cleroda-3,13-dien-15,16-olide. Oncotarget 2017, 8, 78379-78396. [PubMed]

42. Thiyagarajan, V.; Sivalingam, K.S.; Viswanadha, V.P.; Weng, C.F. 16-hydroxy-cleroda-3,13-dien-16,15-olide induced glioma cell autophagy via ROS generation and activation of p38 MAPK and ERK-1/2. Environ. Toxicol. Pharmacol. 2016, 45, 202-211. [CrossRef] [PubMed]

43. Velmurugan, B.K.; Wang, P.C.; Weng, C.F. 16-hydroxycleroda-3,13-dien-15,16-olide and n-methyl-actinodaphne potentiate tamoxifen-induced cell death in breast cancer. Molecules 2018, 23, 1966. [CrossRef] [PubMed]

44. Chen, Y.C.; Huang, B.M.; Lee, W.C.; Chen, Y.C. 16-hydroxycleroda-3,13-dien-15,16-olide induces anoikis in human renal cell carcinoma cells: Involvement of focal adhesion disassembly and signaling. Onco Targets Ther. 2018, 11, 7679-7690. [CrossRef] [PubMed]

45. Riyaphan, J.; Jhong, C.H.; Lin, S.R.; Chang, C.H.; Tsai, M.J.; Lee, D.N.; Sung, P.J.; Leong, M.K.; Weng, C.F. Hypoglycemic efficacy of docking selected natural compounds against alpha-glucosidase and alpha-amylase. Molecules 2018, 23, 2260. [CrossRef] [PubMed]

46. Jhong, C.H.; Riyaphan, J.; Lin, S.H.; Chia, Y.C.; Weng, C.F. Screening alpha-glucosidase and alpha-amylase inhibitors from natural compounds by molecular docking in silico. Biofactors 2015, 41, 242-251. [CrossRef] [PubMed]

47. Huang, P.K.; Lin, S.X.; Tsai, M.J.; Leong, M.K.; Lin, S.R.; Kankala, R.K.; Lee, C.H.; Weng, C.F. Encapsulation of 16-hydroxycleroda-3,13-dien-16,15-olide in mesoporous silica nanoparticles as a natural dipeptidyl peptidase-4 inhibitor potentiated hypoglycemia in diabetic mice. Nanomaterials 2017, 7, 112. [CrossRef]

48. Thiyagarajan, V.; Lin, S.X.; Lee, C.H.; Weng, C.F. A focal adhesion kinase inhibitor 16-hydroxy-cleroda-3,13-dien-16,15-olide incorporated into enteric-coated nanoparticles for controlled anti-glioma drug delivery. Colloids Surf. B 2016, 141, 120-131. [CrossRef]

49. Meng, F.C.; Wu, Z.F.; Yin, Z.Q.; Lin, L.G.; Wang, R.; Zhang, Q.W. Coptidis rhizoma and its main bioactive components: Recent advances in chemical investigation, quality evaluation and pharmacological activity. Chin. Med. 2018, 13, 13. [CrossRef]

50. Ghorbani, A. Mechanisms of antidiabetic effects of flavonoid rutin. Biomed. Pharmacother. 2017, 96, 305-312. [CrossRef]

51. Oboh, G.; Ademosun, A.O.; Ogunsuyi, O.B. Quercetin and its role in chronic diseases. Adv. Exp. Med. Biol. 2016, 929, 377-387. [PubMed] 